\title{
Design of Antiwindup AVR for Synchronous Generator Using Matlab Simulation
}

\author{
Abdelelah Kh. Mahmmod \\ Elect. Eng. Dept. /College of Engineering/ University of Mousl
}

\begin{abstract}
Automatic voltage regulator AVR is designed for synchronous generator utilizing anti windup PI controller, to keep the terminal voltage of the generator to the rated value. The simulation of the synchronous generator is done using Matlab instructions which based on d-q axes models and the designed AVR as anti wind up PI controller. The results shows when an inductive load is applied to the generator the terminal voltage drops, the AVR is automatically increasing the excitation to get rid of this the disturbance as fast as possible.
\end{abstract}

Keyword: Anti windup PI, AVR, Synchronous generator.

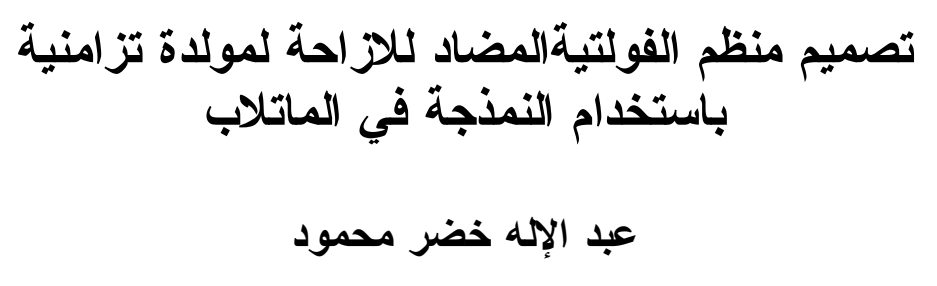

قسم الهندسة الكهربائية / كلية الهندسة / جامعة الموصل

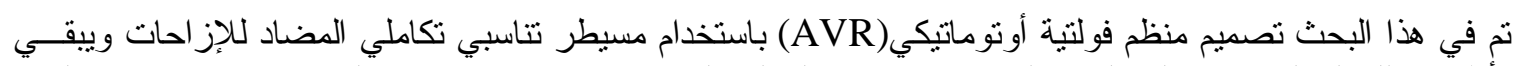

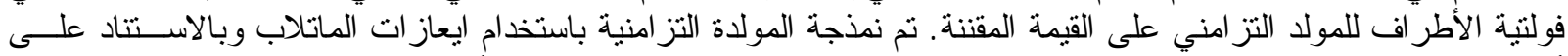

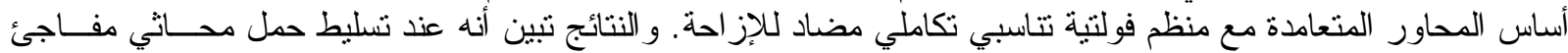

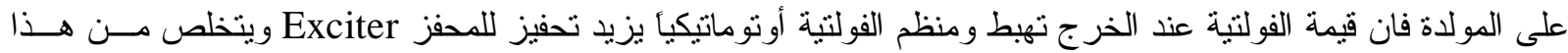

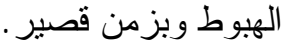

الكلمات المفتاحية : منظم فولتية أوتوماتيكي ، مولدة تز امنية ، مسيطر تتاسبي تكاملي مضاد للاز احة. 


\section{\begin{tabular}{llll} 
Al-Rafidain Engineering & Vol.17 & No.3 & June 2009 \\
\hline
\end{tabular}}

\section{Introduction:}

One of the major auxiliary parts of the synchronous generator is the automatic voltage regulator AVR. The role the of AVR is to regulate the terminal voltage of the synchronous generator whenever any drop in terminal voltage occurs due to sudden or accident change in loading or at any fault occurrence. The AVR also improves the transient stability of the power system. The function of the AVR is to compare a reference voltage $V_{r}$ with a sensed and stepped down transformed and rectified terminal voltage $V_{t}$ or the error signal:

$$
\mathrm{e}(\mathrm{t})=\mathrm{V}_{\mathrm{r}}-\mathrm{V}_{\mathrm{t}}
$$

The excitation to the field winding of the generator will be function of the error voltage. The excitation system controls the generated EMF of the generator and therefore controls not only the output voltage but the power factor and current magnitude, as well.

The excitation control of synchronous generator is needed for stability of overall system and compensating the decrease in terminal voltage. The RMS output terminal voltage of a generator is proportional to the field excitation and may be represented as:

$$
\mathrm{V}_{\mathrm{RMS}}=\mathrm{f}\left(\mathrm{N}_{\mathrm{S}}, \mathrm{Z}, \phi\right) \text {, }
$$

where $\mathrm{N}_{\mathrm{s}}$ is the speed of the prime mover, $\mathrm{Z}$ is the effective number of winding turns in each phase and $\phi$ is the flux per pole. The flux $\phi$ is dependent on the field current $\mathrm{I}_{\mathrm{f}}$. The relation of the field current $I_{f}$ and the flux $\phi$ is not linear all over the operating range. The field current is a direct function of the DC voltage $\left(\mathrm{V}_{\text {out }}\right)$ applied across the field winding. The generator output voltage my be represented as:

$$
\mathrm{V}_{\mathrm{RMS}}=\mathrm{f}\left(\mathrm{N}_{\mathrm{S}}, \mathrm{Z}, \mathrm{V}_{\text {out }}\right)
$$

For an ac generator, the supply frequency is kept constant by keeping the prime mover speed constant by using a governor. From (2) it is evident that terminal voltage depends upon the field dc supply $\left(\mathrm{V}_{\text {out }}\right)$. There are various types of excitation system and controllers. The applied control methods for these types may be realized as analog or digital. The excitation of synchronous generator to field winding has the form of:

(1) A DC generator driven by either steam turbine [prime mover] mounted on the same shaft of the generator or AC induction generator with high frequency.

(2) Static exciters which are solid-state devises widely used now days. These devices may consist of some form of rectifier bridge on the rotor, or thyristor bridge type with firing angle controlled. Other types are Chopper type excitation with triggering to the base of the power transistor. The main power for the system is supplied either from the AC bus of the generator, which called self excited or from pilot exciter.

The speed response of the AVR is of great interest in studying the performance and stability of system. Because of the high inductance in the generator field winding, it is difficult to make rapid changes in field current. This introduces a considerable lag in the control function and is one of the major obstacles to be overcome in designing a regulator system.

\subsection{Review of Publications:}

The original report which published by IEEE committee recommended four types of AVR structures and for different and various synchronous generators machines [1]. Then, later many researchers and designers worked on it as computer program simulation for AVR realization $[2,3,4]$. The excitation of synchronous generator becomes with great interest of researchers and they implement power electronic devices like thyristors bridge or choppers $[5,6,7]$. The AVR 


\section{Abdelelah : Design of Antiwindup AVR for Synchronous Generator Using Matlab}

may be realized as analog circuits [8,9] or digitally realized[10]. Another role of the AVR is to stabilize system at occurrence of any disturbances [11].

In this work the synchronous generator is simulated with Matlab and an AVR is designed in the form of anti windup PI controller to eliminate saturation of the exciter and realized as analog circuit configuration controller and as a digital controller.

\section{Simulation of Synchronous Generator:}

The synchronous generator is modeled on the base of direct and quadrate axes for sub transient generated voltages $\mathrm{E} \mid$ " and for armature current in the direct and quadrate axes Id, Iq which is shown in Fig. (1) by simulation with Matlab[12].

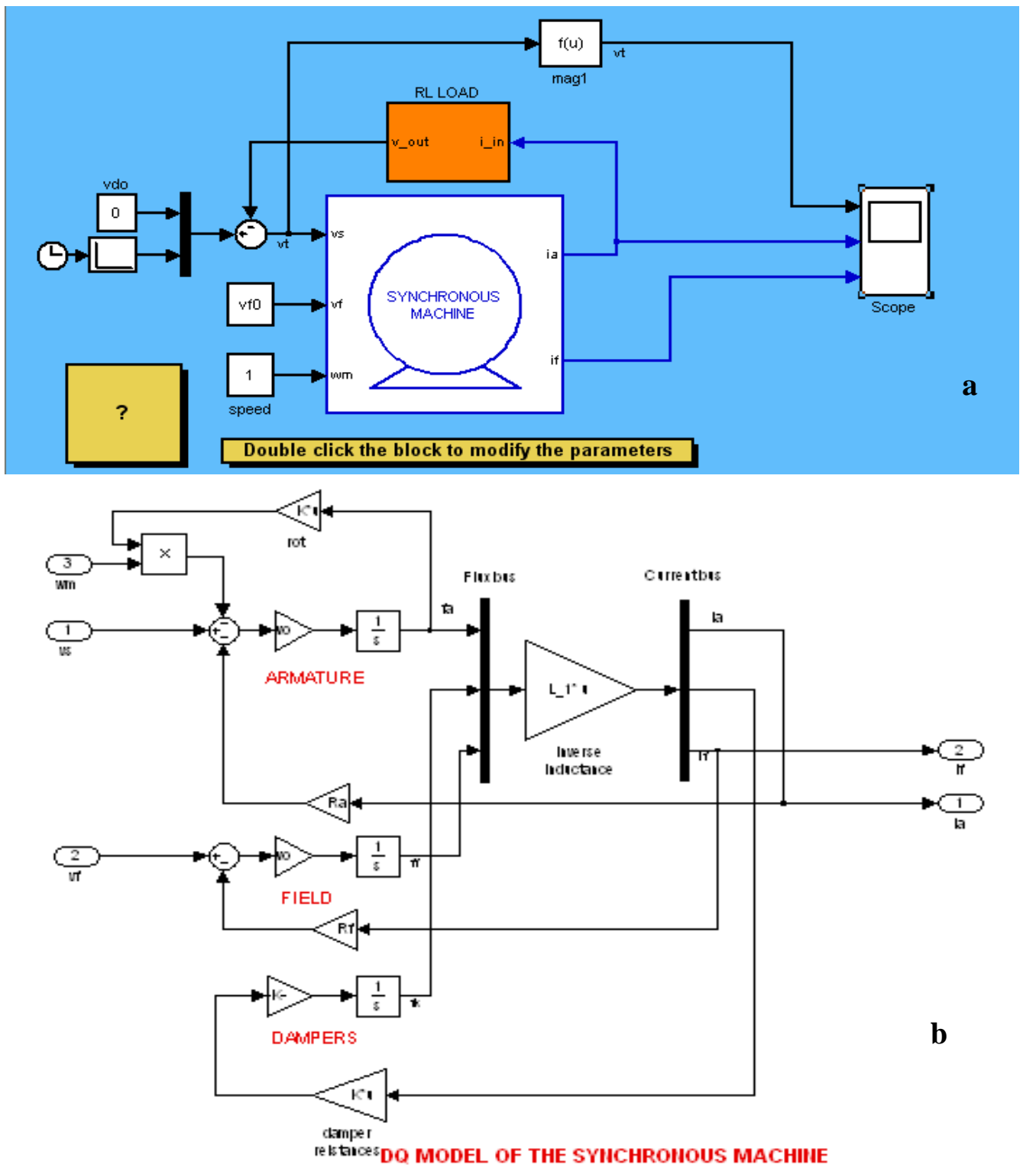

(1a, b) Fig.

Simulation for Synchronous Generator Using Direct and Quadrate Axes 


\section{Al-Rafidain Engineering}

\subsection{Identification of Transfer Functions:}

The inductive load is applied at time $0.5 \mathrm{sec}$. with the speed of synchronous generator is assumed constant value. The transient response for the terminal voltage and current is shown in Fig. (2). From the transient response, the time constant can be found by calculating the time $\tau$ when the voltage reaches $63 \%$ of the final value or $37 \%$ of its final value for the decaying transient response. The transfer function is identified as:

$$
\mathrm{G}_{\mathrm{p}}(\mathrm{s})=\frac{\mathrm{K}_{1}}{\tau \mathrm{s}+1} \text {, Where } \tau=1.7 \mathrm{sec} \text {. and } \mathrm{K}_{1} \text { is the final } \mathrm{DC} \text { value. In this case it is unity }
$$
because per unit is used.
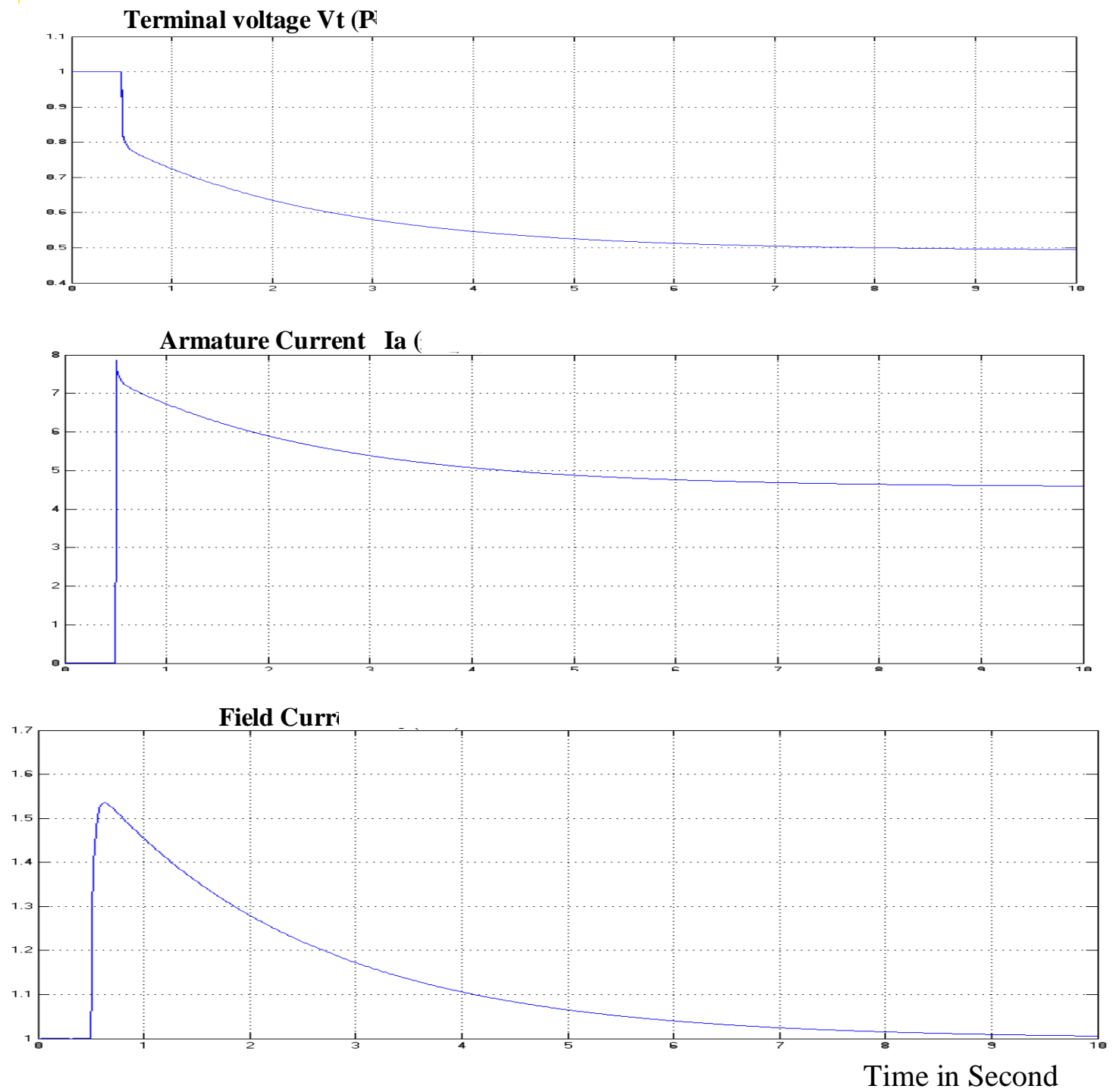

Fig. (2)

Transient Response for the Terminal Voltage $\left(V_{t}\right)$ Armature Current, $I_{a}$, Filed Current $I_{f}$. 
Abdelelah : Design of Antiwindup AVR for Synchronous Generator Using Matlab

\subsection{Simulation of Exciter:}

The exciter is simulated as a transfer function between the applied excitation voltage and the current which generate the EMF in the winding. The model is given as:

$$
\mathrm{G}_{\mathrm{e}}(\mathrm{s})=\frac{1}{0.1 \mathrm{~s}+1}
$$

This is the transfer function of the block diagram after PI controller and before synchronous generator block in Fig. (3).

\section{Design of PI Control AVR:}

The overall block diagram representation of the generator and exciter and the controller is shown in Fig. (3), when the terminal voltage is compared with reference voltage which generates the error signal.

$\mathrm{e}(\mathrm{t})=\mathrm{r}(\mathrm{t})-\mathrm{v}(\mathrm{t})$, then the PI controller output is given in Laplass transform as:

$\mathrm{U}_{\mathrm{c}}(\mathrm{s})=\mathrm{Kp} \mathrm{E}(\mathrm{s})+\mathrm{K}_{\mathrm{i}} / \mathrm{s} \mathrm{E}(\mathrm{s})$

The transfer functions of the PI controller given as:

$\mathrm{G}_{\mathrm{c}}(\mathrm{s})=\frac{\mathrm{U}(\mathrm{s})}{\mathrm{E}(\mathrm{s})}=\frac{\mathrm{K}_{\mathrm{i}}\left(1+\mathrm{T}_{\mathrm{i}} \mathrm{s}\right)}{\mathrm{s}}$, where $\mathrm{Kp}, \mathrm{Ki}$ are constants, $\mathrm{T}_{\mathrm{i}}=\mathrm{K}_{\mathrm{p}} / \mathrm{K}_{\mathrm{i}}$

The design method is to find $\mathrm{K}_{\mathrm{p}}, \mathrm{T}_{\mathrm{i}}, \mathrm{K}_{\mathrm{i}}$ for a desired specification.

1. Fast rise time $t_{r}=0.7 \mathrm{sec}$.

2. Fast settling time $t_{\mathrm{s}}=1.7 \mathrm{sec}$.

3. Lower maximum overshoot $=13 \%$.

The tool which is used in this work is designing by SISO tool in Matlab shown in Fig. (4). In this method is the plant transfer function is given in the work space by Matlab instruction given below.

$\mathrm{G}_{1}=\mathrm{tf}\left(\left[\begin{array}{ll}0 & 1\end{array}\right],\left[\begin{array}{ll}1.7 & 1\end{array}\right]\right) ; \mathrm{G}_{2}=\mathrm{tf}\left(\left[\begin{array}{ll}0 & 1\end{array}\right],\left[\begin{array}{ll}0.1 & 1\end{array}\right]\right) ; \mathrm{C}=\mathrm{tf}\left(\left[\begin{array}{ll}\mathrm{kp} & \mathrm{kd} . \mathrm{T}\end{array}\right],\left[\begin{array}{ll}1 & 0\end{array}\right]\right)$

$\mathrm{G}_{3}=$ Series $\left(\mathrm{G}_{1}, \mathrm{G}_{2}\right)$; Sisotool $\left(\mathrm{G}_{3}\right)$

The PI controller designed by giving the unknown PI controller parameters in the UGI shown in Fig (4) as block C.

The values of $\mathrm{Kp}, \mathrm{Ki}$ and $\mathrm{Ti}$ are chosen to achieve a satisfied performance specification.

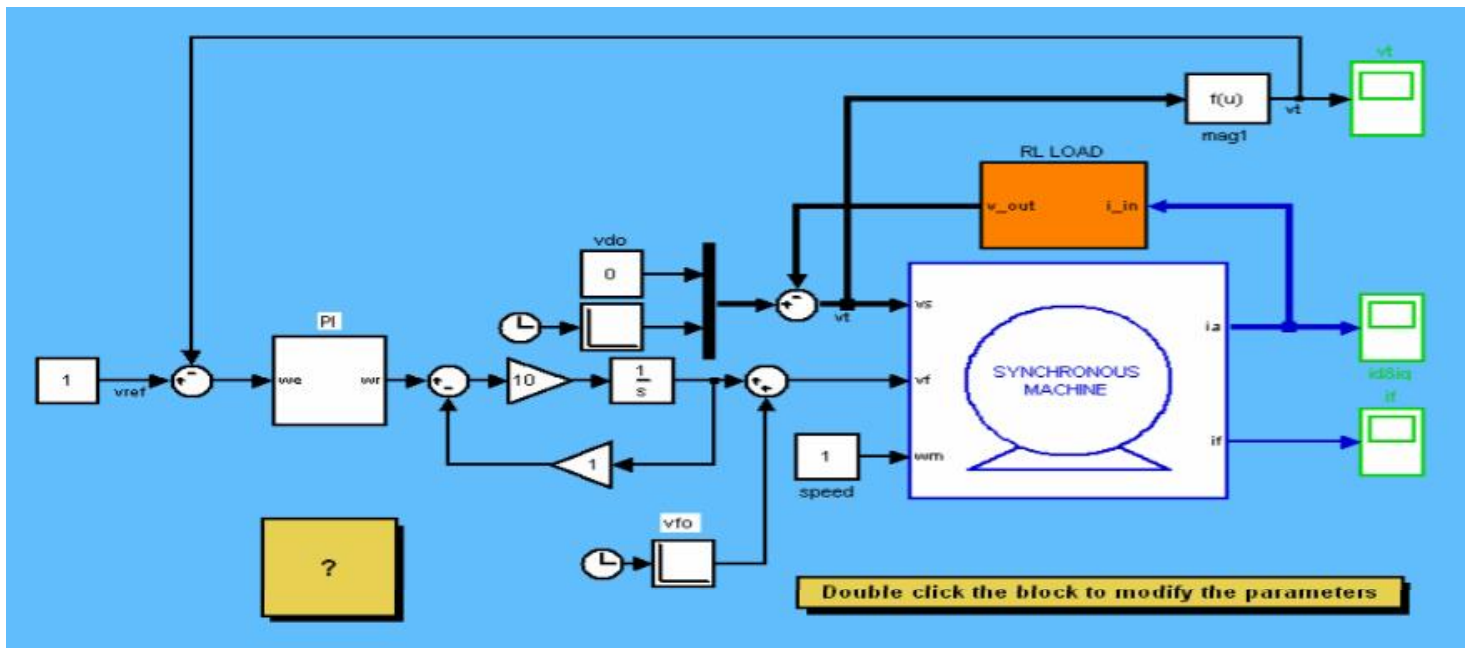

Fig. (3): Overall Simulation of Synchronous Generator, Exciter, Controller 


\begin{tabular}{llll} 
Al-Rafidain Engineering & Vol.17 & No.3 & June 2009 \\
\hline
\end{tabular}

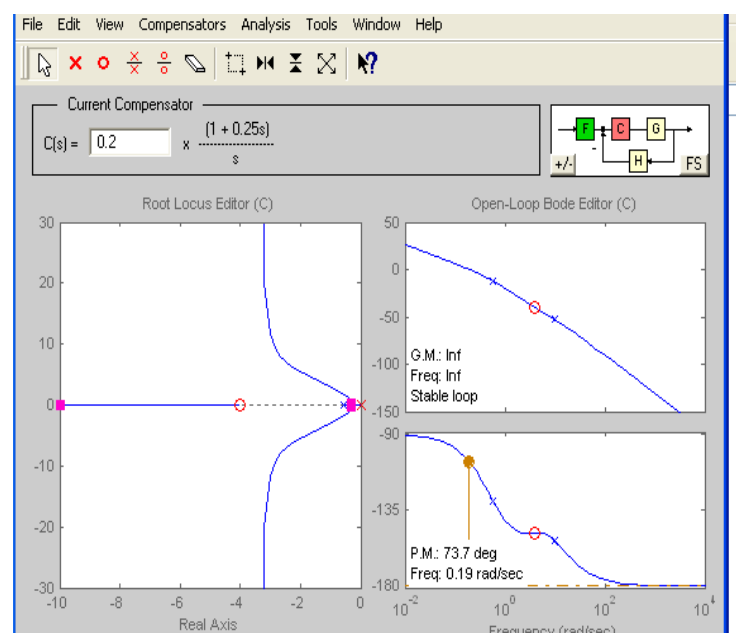

Fig. (4): UGI SISO Design Tool

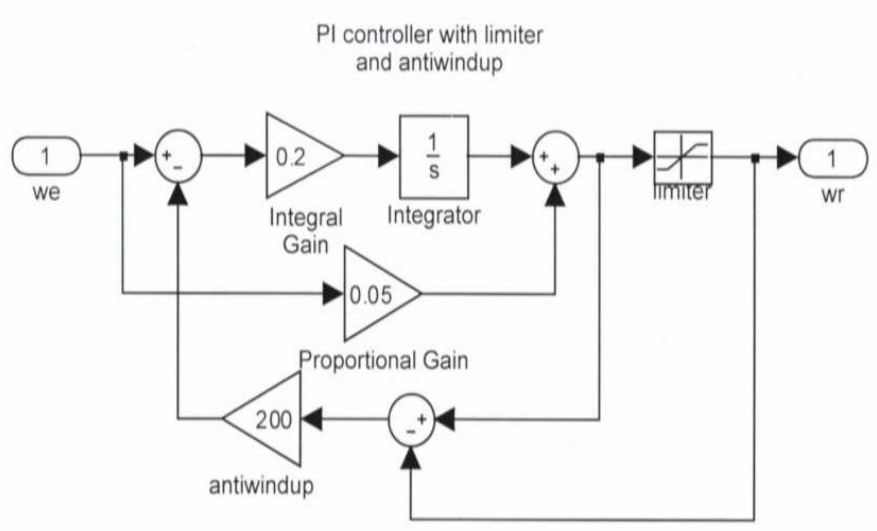

Fig. (5): Anti windup PI Controller

\section{Anti windup PI Controller:}

The process to avoid saturation of the exciter that introduced from large value of integration error from integrator part of PI controller is called integrator wind up. To eliminate it anti windup is used. Several ways to avoid integrator windup one possibility is to stop updating the integral when exciter is saturated. Another method, where extra feedback path is provided by measuring the exciter output and forming an error signal as difference between the exciter output $U_{c}$ and the controller output $\mathrm{V}$ and feeding this error back to the integrator through gain $\frac{1}{\mathrm{~T}_{\mathrm{t}}}$. The error signal is zero when actuator is not saturated. But when the actuator is saturated the extra feedback path tries to make the error signal equal to zero. This means that the integrator is rest, so that the controller output is at the saturation limit. The integrator is thus rested to appropriate value with time constant $T_{t}$., which is called tracking time constant. This method for anti windup can be applied also for actuator with arbitrary characteristics, such as dead zero or hysterics. If the actuator output is not measured, the actuator can be modeled in the controller output and the equivalent signal can be generated from model to reset the integrator.

The antiwindup AVR shown in Fig. (5), the exciter saturation is modeled in the controller by cascading it with output of PI controller. The difference between the output of saturation model and its input is feedback to the controller with gain $\frac{1}{T_{t}}=200$. The overall antiwindup PI controller shown in Fig. (3), the role of AVR is to regulate the terminal of voltage whenever any drop occurs. It is shown that a load is applied suddenly at $0.5 \mathrm{sec}$., the terminal voltage is regulated during about $1.7 \mathrm{sec}$. automatically as shown in Fig. (6). 
Terminal voltage $\mathrm{Vt}(\mathrm{PU})$

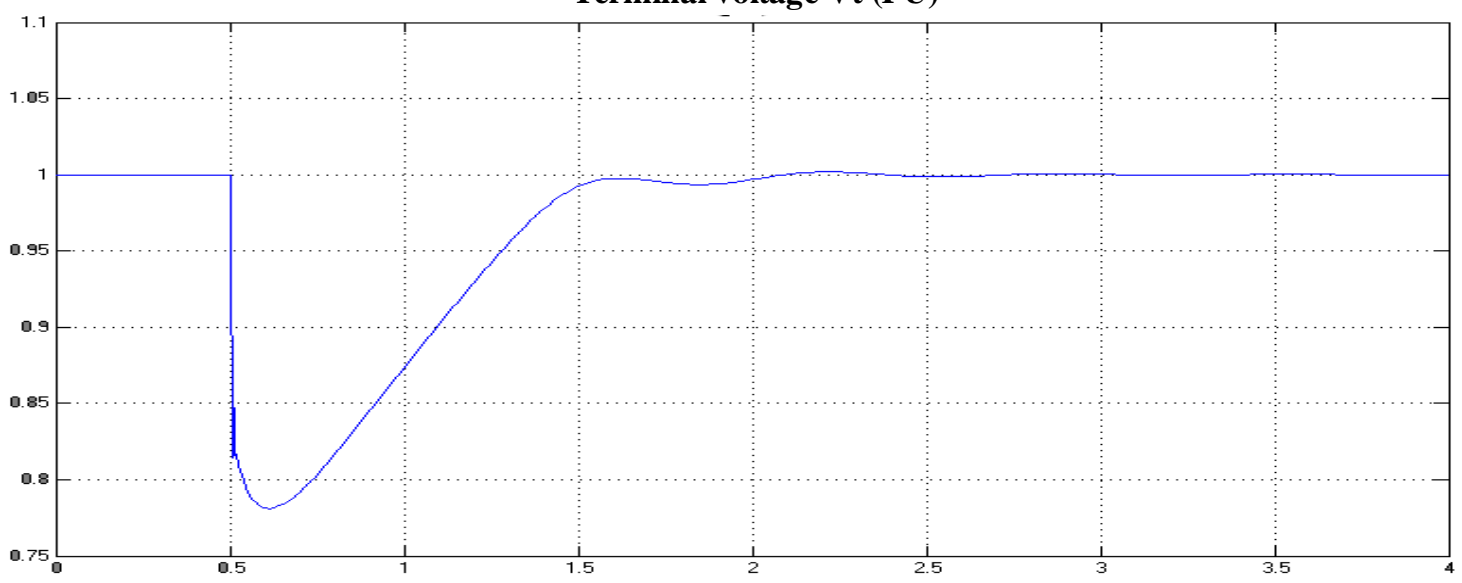

Armature Current Ia (PU)

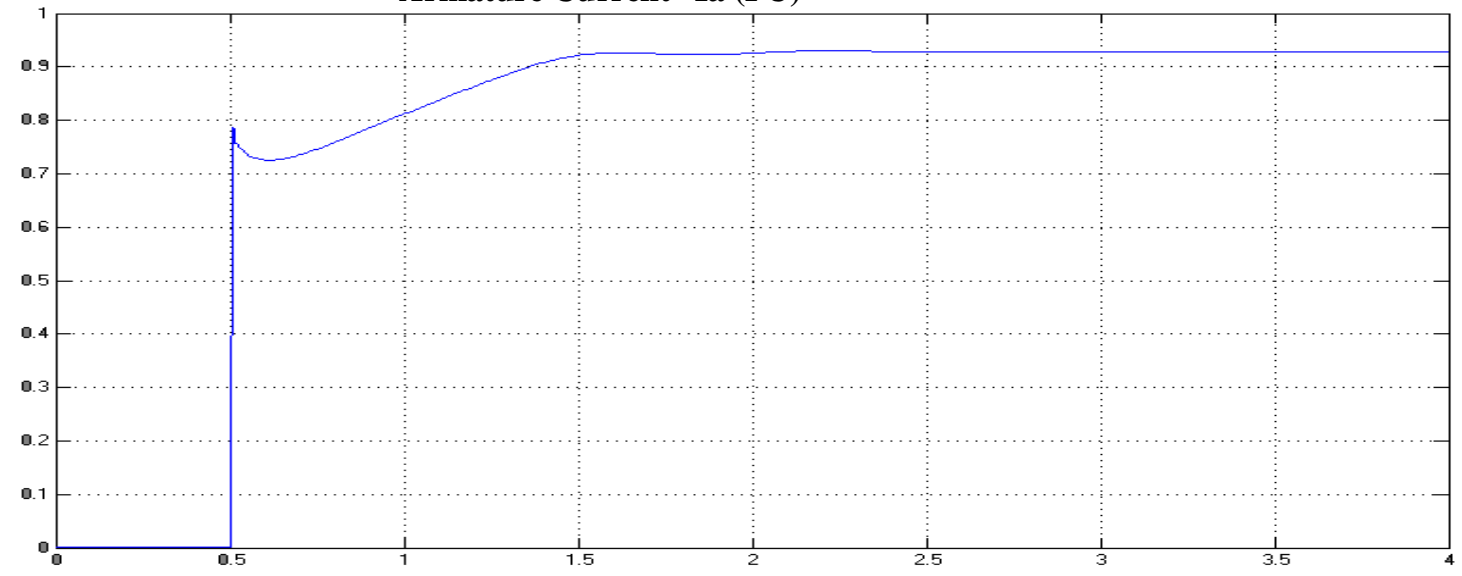

Field Current $I_{\mathbf{f}}(\mathbf{P U})$

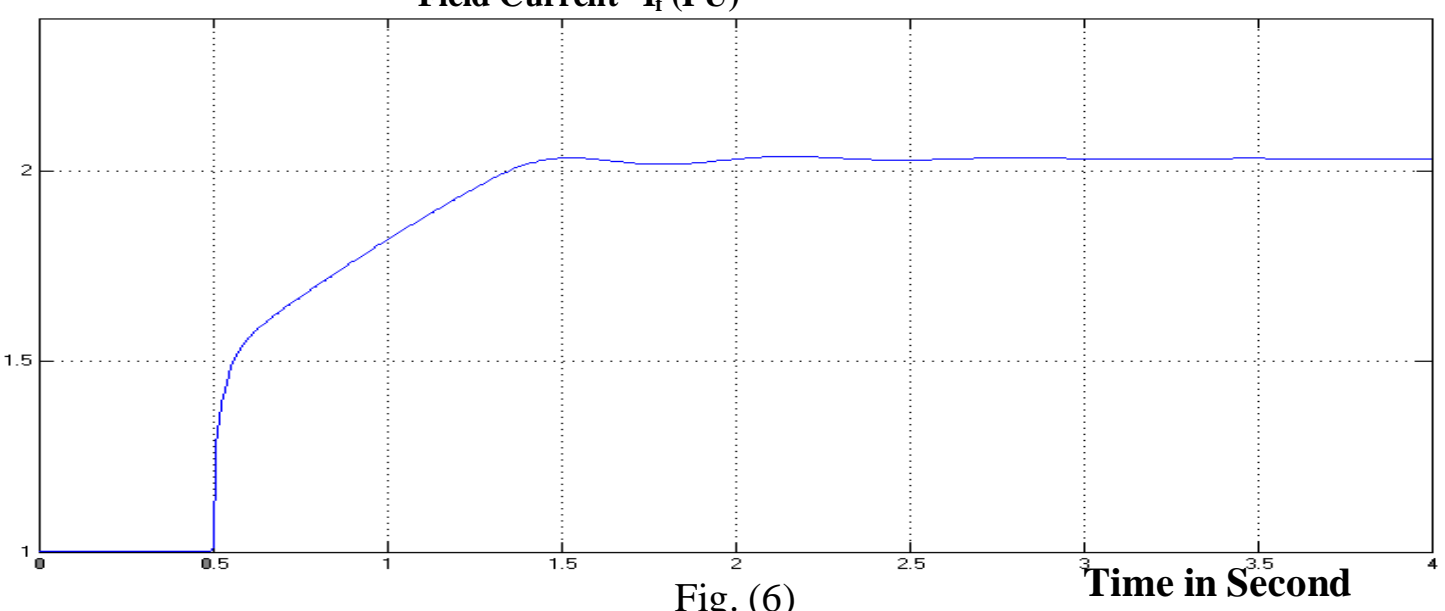

Transient Response of the Closed Loop System with AVR at Load in $0.5 \mathrm{Sec}$. 


\section{Realization of the PI Controller:}

Realization of anti windup controller may be analogue or digital. The analog can be realized by operational amplifiers OPAMP configuration shown in Fig. (7). While the digital one can be realized by uses of interfacing or data acquisition system (DAQ) to inter data to the $\mu$-computer or $\mu$-controller. The role of DAQ is to inter the sensed data as a word and the $\mu$-computer performs the given anti windup controller, by programming the algorithm of PI controller with antiwindup. The digital block diagram of the anti windup PI controller AVR given in figure (8) in which the integration is performed by trapezoidal method where $\mathrm{T}$ is sample time period, $\mathrm{kp}$, $\mathrm{ki}$ is the PI parameter of the controller which is designed by sisootool.

The anti windup digital PI controller is performed with given algorithm:

$$
\mathrm{U}(\mathrm{k})=\mathrm{U}(\mathrm{k}-1) \mathrm{K}_{\mathrm{p}} \mathrm{e}(\mathrm{k})+\frac{\mathrm{K}_{\mathrm{i}} \mathrm{T}}{2} \sum\{\mathrm{e}(\mathrm{k})+\mathrm{e}(\mathrm{k}-1)\}-\frac{1}{\mathrm{~T}_{\mathrm{t}}} \mathrm{m}(\mathrm{k})
$$

Where $\mathrm{m}(\mathrm{k})$ is the difference between the input and output of the modeled saturation characteristic.

The actuator saturation is realized as software, and the input to the saturation is saved and compared with the output of the saturation characteristic, and the difference $\mathrm{m}(\mathrm{k})$ is negatively feedback through the integration by gain $\frac{1}{T_{t}}$ therefore the integrator resets when the difference $\mathrm{m}(\mathrm{k})$ is not equal to zero

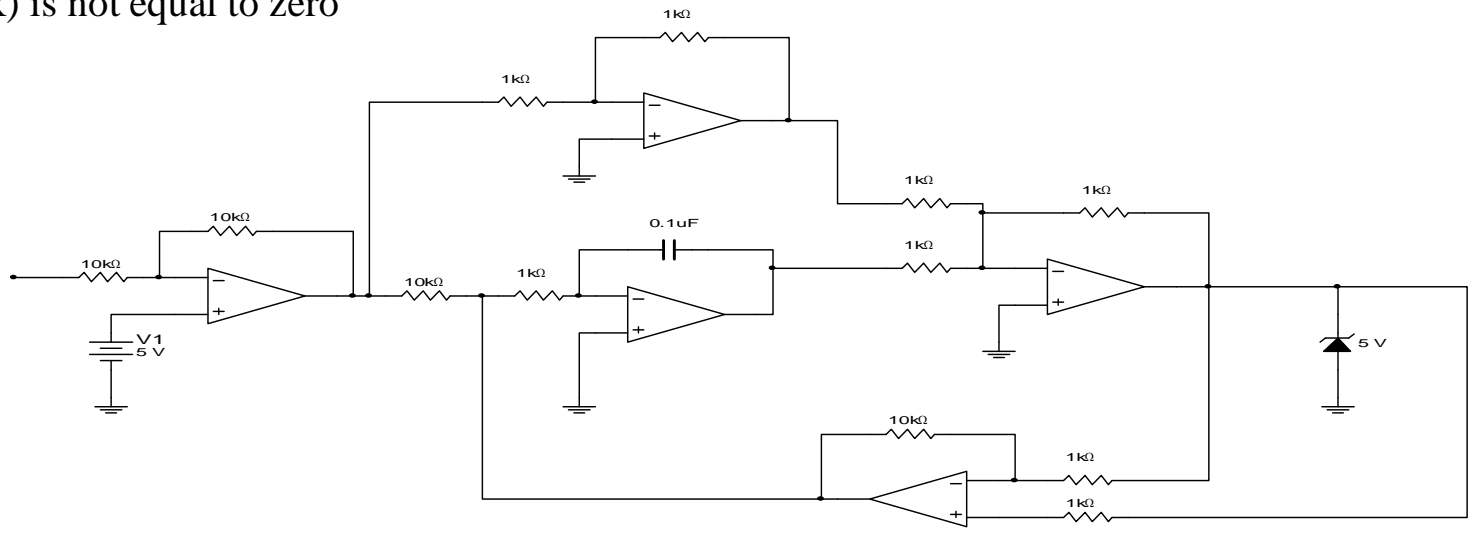

Fig. (7) Realization of Anti Windup Analog Controller with OPAMP Configuration

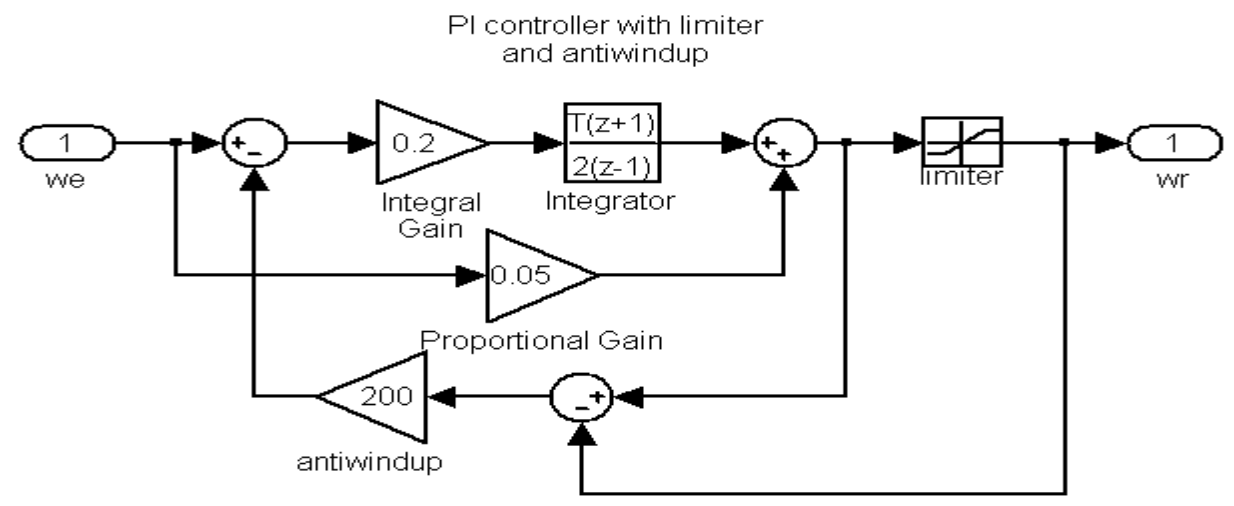

Fig. (8): Digital Block Diagram of Anti Windup PI Control 


\section{Results and Conclusions:}

The synchronous generator was modeled by Matlab instructions on the base of direct and quadrate axes. The inductive load was applied to the generator at $0.5 \mathrm{sec}$ the AVR regulates the terminal voltage by increasing the excitation automatically with fast rise time and short settling time. When the parameter of PI controller is changed the transient response will be oscillatory and take long time to improve terminal voltage, the anti windup is used to reset the controller integrator when the actuator is saturated. The anti windup can be used for elimination of other forms of non linearity like dead zone and hysteresis and others.

\section{References:}

1- IEEE Committee Reports "Computer Representation of Excitation System". IEEE trans. on Power Apparatus and System, Vol. PAS 87, No. 6, June. 1968.

2- G. M. Pavlov, G. V. Merkurbev. "Automatica in Energy System". C. Peterburg 2001.

3- C. L. Brasca \& M. A. Johnson, "On Automatic Voltage Regulator Design for Synchronous Generators", IEEE International Conference on Control and Applications, Vol. 1, No. 3, Aug. 1994.

4- M. S. Ghazizadeh \& F. M. Hughes, "A Generator Transfer Function Regulator for Improved Excitation Control", IEEE Transfer on Power Systems, Vol. 13, No. 2, May 1998.

5- Muhammad H. Rashid, "Power Electronics Circuits, Devices and Applications". Pearson Edu. Int. $3^{\text {rd }}$ ed. 2004.

6- R. C. Schaeter, "Applying Static Excitation Systems", IEEE Industry Application, Magazine November, December 1998.

7- A. Mirdoch and J. J. Sanchez-Gasca, M. J. D'Antonio and R. A. Lawson, "Excitation Control for High Side Voltage Regulation", Panel Session Summary for the IEEE/PES 2000 SPM, Seattle, WA.

8- Angelo J. J. rezck \& Carlos Alberto D-Coelho, "The Modulus Optimum (MO) Method Applied to Voltage Regulation Systems: Modeling, Tuning and Implementation", EFEI-ESCOLa Federal de Engenhana de Itajuba, AV. BPS, 1303 Itajuba-MG-Brazil 37500-903. E-Mail rezek@iee.efei.br.

9- Claudio Saldana, Graciela Calzolari, and Gerardo Cerecetto, "ATP Modeling and Field Tests of the AC Voltage Regulator in the Palmar Hydroelectric Power Plant", International Conference on Power Systems Transients-IPST 2003 in New Orleans, USA.

10- Kiyons Kim. Richard C. Schaeter. "Tuning a PID Controller for a Digital Excitation Control System". IEEE Trans. On Industry Application Vol. 41, No. 2, March/April 2005.

11-P. M. Anderson and A. A. Fouad, "Power System Control and Stability", IEEE Press, 1995.

12- "SIMULINK Dynamic System Simulation for MATLAB", The Mathworks Inc., 2000. 